\title{
Development Strategy of China's Marine Engineering Science and Technology for 2035
}

\author{
Task Force for the Research on China's Engineering Science and Technology Development Strategy 2035 Marine \\ Research Group
}

\begin{abstract}
Critical and long-term strategic goals for China are to enhance its capacity for exploiting marine resources, develop its marine economy, protect the marine ecological environment, uphold maritime rights and interests, and establish itself as a maritime power. However, China is still in the preliminary stage of marine exploration; therefore, we need to enhance our capability to utilize and control the oceans, from a global perspective. It is imperative that the development and utilization of marine resources-including exploration, engineering exploitation, and environmental protection - and safeguarding of the rights and interests of the state be treated as an organic whole in top-level engineering science and technology designs, which are prerequisites to establishing a maritime power. Based on a series of technology foresight analyses, performed through inter-disciplinary integration, this project proposes the key directions in marine engineering science and technology (S\&T) development. In addition, this paper outlines the development path for China's marine engineering S\&T in six key aspects: marine environment stereo-observation technology and equipment, submarine resource exploration and development technology, marine biological resource exploration and development technology, technology for comprehensive utilization of seawater resource and marine energy, marine environment security technology, and marine development equipment. This paper presents the scientific and technological vision, key points of development, development strategy, and development path for China's marine engineering S\&T to be achieved by 2035.
\end{abstract}

Keywords: marine engineering science and technology; development strategy; technology foresight; maritime power

\section{Introduction}

With the growing shortage of land resources, deterioration of living environment, and increasingly severe challenges accompanying political and human rights issues, a "blue revolution," marked by marine development, is emerging worldwide as a new driver of global social and economic development. In the 21 st century, the oceans, as a new pool of resources for the entire world, have considerable social and economic significance and are crucial to national security and strategic interests [1-4]. Therefore, China has launched a key development strategy aimed at its emergence as a maritime power. The report of the 18th National Congress of the Communist Party of China explicitly pointed out the need to enhance China's capabilities of marine resource exploration, development of marine economy, protection of the marine ecological environment, and resolutely safeguarding national marine rights and interests as key components of China's development into a maritime power. A maritime power shall demonstrate adequate knowledge and stewardship with regard to exploiting oceans. Deep insights into marine issues are prerequisites to marine management and planning. China shall adopt a global outlook with respect to formulating a strategy for intensive development and optimal use of coastal and offshore resources, the exploitation of seabed resources at high seas, and developing scientific awareness of the deep seas and the polar regions.

A modern marine economy consists of activities that exploit the seas; these activities rely on marine spaces and the activities of related services. China has put forth a five-pillar development concept to suit the new era: "innovative, coordinated, green, open, and shared." When compared to the land-based economy, marine economic activities are more focused on international

Received date: 26 December 2016; revised date: 12 January 2017

Corresponding author: Pan Delu. E-mail: pandelu@sio.org.cn; Li Teng. E-mail: liteng@sio.org.cn

Funding program: CAE Advisory Project “Research on China’s Engineering Science and Technology Development Strategy 2035” (2015-ZD-14)

Chinese version: Strategic Study of CAE 2017, 19 (1): 108-117

Cited item: Task Force for the Research on China's Engineering Science and Technology Development Strategy 2035 Marine Research Group. Development Strategy of China's Marine Engineering Science and Technology for 2035. Strategic Study of CAE, https://doi.org/10.15302/J-SSCAE-2017.01.016 
affairs. In addition, the exploitation of marine resources is shifting from depredatory use to sustainable development. Oceans are spread widely and change dynamically. Therefore, the exploitation of both high and deep seas is primarily contingent upon having strong competencies in environmental and resource exploration and on the associated engineering technology for safety and security reassurance. Secondly, China's marine development is at an early stage. Engineering development and national interest protection need to be considered as an organic whole to establish a clear development strategy through technological foresight, by integrating interdisciplinary studies, for marine resource exploration. In this context, the Task Force studied the 2035 development strategy for the advancement of China's marine engineering science and technology (S\&T), with the aim of expediting the pace toward becoming a maritime power, developing the core competencies necessary for addressing international disputes that are likely to arise in the course of marine development, and supporting the great-leap-forward development of China's marine engineering S\&T.

\section{Development vision of China's marine engineering S\&T for 2035}

Among all scientific studies, engineering S\&T is most directly connected to socio-economic and industrial development. Studies on development strategies of marine engineering S\&T must focus on the demands of national socio-economic development, with particular attention to the evolution of their demands as well as to the feasibility and applicability of these S\&T projects. Within two decades, marine engineering S\&T shall be based on a global perspective and centered on the development of a maritime power with a high degree of safety and sustainability, in order to enhance China's international maritime status and discourse power. Two major aspects of the 2035 development vision for China's marine engineering capabilities are discussed below:

(1) Establishing independent technology framework for marine equipment and setting up a primary global marine safety assurance network system supported by the capabilities of intelligent marine environment monitoring and ocean management and planning competencies

In future, China will achieve significant advances in its capabilities to develop marine exploitation equipment and become a technical leader and standard-setter in the field. Endowed with the core technology of high-end marine exploitation equipment, China will be capable of providing modernized equipment for multi-dimensional ocean observation and other marine exploration and exploitation activities. China will develop multidimensional marine monitoring and early-warning capabilities that enable rapid coverage of the oceans around the globe and continuous surveillance of key oceanic regions. A sophisticated technical system that will provide reassurance to national security and strategic interests will lay a solid foundation for advanc- ing deep into the oceans and maintaining the status of a maritime power.

(2) Acquiring reasonable resources of marine space and capabilities of exploring and exploiting seabed mineral resources and marine biological resources in deep and high seas as well as that of comprehensive utilization of seawater resource and ocean energy at an industrial scale, while the marine economy and industry increase significantly

While addressing the challenges of economic restructuring and structural adjustment, China did not completely exploit marine resources, which have unlimited potential and will become a new growth point for the development of China's economy. By 2035, China will have advanced to a "blue economy" at an industrial scale, developed a technical system for fine exploration of seabed ore deposits, completed sea trials and practical application of $1000 \mathrm{~m}$ deep-sea ore collection and conveying technology, and established pilot technological projects of seabed ore deposits and natural gas hydrates exploration and exploitation; realized commercial utilization of deep and high sea marine geological resources (including species, genetic, and product resources); and achieved the world's most advanced technology for the comprehensive utilization of seawater resource and marine energy. Simultaneously, China will be capable of green development and sustainable technology for marine ecological and environmental protection and marine management, which will ultimately result in the scientific, orderly, and sustainable exploitation of marine resources [5-7].

\section{Frontiers and development trends of global marine engineering $S \& T$}

\subsection{Widespread implementation of multi-dimensional marine observation, forecasting, and intelligent information service systems}

The construction of a multi-dimensional ocean observation network is critical to the development of future marine S\&T. The frontier issues in the marine observation field include the following: satellite remote-sensing marine environment observation in a multiple-parametric, wide ranging, real time, and multidimensional manner; a miniature, intelligent, standardized, and industrialized sensor; and a globalized, multi-layered, comprehensive, smart ocean network observation. Numerous countries are focusing on marine observation technology integration and service systems, particularly, the widely employed multidimensional observation network represented by the "satellitespace-sea and surface-water-seabed smart networking" technology. Examples are the US integrated ocean observing system (IOOS), pan-European ocean monitoring and forecasting service system (MyOcean), global ocean observing system (GOOS), and the global earth observation system of systems (GEOSS), which enable the formation of a network for long-term observation, 
monitoring, and information provision at global and regional scales. In the long run, the leading direction should be toward a multi-platform, self-adaptive, and multi-dimensional ocean observation network oriented toward satisfying the demands of maritime activities and providing marine information service.

A marine numerical forecasting system is crucial to ensure ocean safety. With super computers, real-time acquisition of ocean monitoring data, development of data assimilation technology, and maturity of efficient parallel technology, the development of a seamless, ultra-high definition, and numerical marine forecasting system has become a major approach toward ensuring marine safety and is actively pursued by numerous countries. The goal will shift from the conventional dynamic environmental security of the ocean to an all-round security covering the ecological environment, resource exploitation activities, and marine rights and interest expansion.

Global or regional marine big data will be collected by a realtime and multi-dimensional ocean observation and forecasting system. Through an intelligent service system, such big data will be utilized widely in various ocean safety services and exploitation activities and will thus result in the industrialization of ocean information services.

\subsection{Diversity, precision, and safety of ocean resource exploration and exploitation of high and deep seas}

The exploration and exploitation of resources at the sea bottom have been integrated into the national strategies of the world's maritime powers. Global technological approaches tend to become more diversified, more precise, safer, more efficient, and wide ranging and sea bottom accessible. Currently, deep-sea solid ore exploitation has become practical, while due consideration is accorded to its environmental impact. In 2013, Japan performed a trial exploitation of gas hydrate on the Nankai Trough, and it was a valuable attempt toward commercial exploitation. In 2014, the EU launched a large scale deepsea ore mining initiative (Blue Mining), which was aimed at the multi-dimensional exploration and exploitation of deep-sea polymetallic nodules and sulfides, which exist as deep as 6000 m. In 2015, Specialist Machine Developments Limited (SMD), a subsidiary of China's Zhuzhou CRRC Times Electric Co., Ltd., announced the development of the world's first set of deep-sea ore mining equipment.

Exploration and exploitation of marine biological resources is evolving toward precision, digitalization, and information system integration. Technologically advanced nations and regions have started employing 4S (RS, GIS, GPS, and VMS) technology to upgrade their fishing resource exploitation and monitoring capabilities in the open seas. Thus, they have acquired a deeper understanding of the fluctuations in fishery resources and changes in fishing grounds. These high-end technologies are propelling the rapid development of competencies and equipment for exploring new massive fishing resources at high seas. Deep- and high-sea biological genetic resources and product resources have become the focus of marine biological technology development Examples are the research and development of marine bioenzymes, including the "Life at Extreme Environments" initiative of the United States; the "Coldzyme" and "Extremophiles as Cell Factory" initiatives of the European Union; Germany's "BioCatalysis2021" project; and the "Research and Development of Marine Biologic Enzyme" initiative under China's National "863 Program." It is foreseeable that the scaled development of marine biological enzymes will exert deep and far-reaching impact on the marine biological industry.

While significant progress has been made in the exploration and exploitation of marine resources, technological development for safeguarding the marine ecological environment and marine rights and interests is advancing at an expedited pace. The key subjects of marine engineering S\&T include reef ecosystem protection technology, which focuses on the comprehensive restoration of crucial functional organisms in an ecosystem; reproduction of habitats; and complete functional restoration. They also include high-precision seafloor detection technology for the delimitation of the continental shelf, for which interest is shifting from studying characteristics and processes to understanding dynamic mechanisms.

\subsection{Technology for effective and comprehensive use of seawater and marine energy resources}

The first problem to be solved is to reduce energy consumption and cost to ensure the efficient utilization of seawater and ocean energy resources. A few countries are making aggressive research efforts toward membrane-based approaches to seawater treatment in anticipation of technical breakthroughs in seawater desalination; this is in order to acquire the maximum possible share of the desalination market, while safeguarding their own usable seawater resource. In the field of marine energy exploitation, tidal energy and off-shore wind power have already been used commercially. Pilot projects for the scaled use of tidal current energy, wave energy, and high-sea wind power have been established, and thermal energy and salinity energy technologies are being tested in the sea. However, as a common global issue of marine energy engineering, effort is still required toward achieving high efficiency and effectiveness, high reliability, high stability, high serviceability, and low cost.

Exploitation of seawater resource and marine energy is attracting significant research and development (R\&D) efforts. Characteristic large projects in the field of seawater exploitation include Japan's mega-ton water system project, which employs membrane processes to produce a million tons of fresh water daily, and South Korea's "Seawater Engineering and Architecture of High Efficiency Reverse Osmosis (SEAHERO)" project and those in the field of marine energy exploitation include the 
UK's "Innovate UK" project and the "US Department of Energy (DOE)'s hydropower projects."

\subsection{Marine exploitation equipment to be more intelligent, integrated, and extended to higher and deeper seas}

All maritime states of the world have invested enormous resources in $\mathrm{R} \& \mathrm{D}$, manufacture, operation, and management of marine exploitation equipment. Particularly, in recent years, the rapid development of technology in the information, materials, and energy fields has facilitated the emergence of a new style of marine equipment, which integrates sensor technology, communication technology, "Internet Plus" technology, advanced materials technology, and power system integration technology. Thereby, it is increasingly influencing the structural transformation and industrial development of the marine engineering sector.

Marine exploitation equipment is evolving toward being intelligent, integrated, and orientated toward high and deep seas. The Internet, big data, intelligent control, and artificial intelligence technologies support this tendency toward becoming intelligent. As a solution to addressing the challenging underwater environment, autonomous underwater vehicles have become increasingly important as tools, and it is likely that they will attain a high level of intelligence for motion control, planning, and decision-making [8]. In terms of becoming integrated, known international market players have been working on system integration and are currently capable of presenting integrated marine engineering solutions. Furthermore, marine engineering equipment is empowering marine exploitation activities for extending to farther and deeper seas. America, Japan, and an increasing number of other countries are developing submersible vehicles that can operate as deep as $10000 \mathrm{~m}$ underwater.

\section{Technology foresight analysis of marine engineering S\&T for 2035}

\subsection{Technology foresight survey}

We performed a technology foresight survey by various means such as expert workshops and correspondence seminars.
Thereby, we obtained 52 technological options. Then, two rounds of questionnaire surveys were performed: (1) In the first round (August to September 2015), we invited 937 experts to participate, out of which 375 accepted (a participation rate of $42.02 \%$ ). A total of 2561 questionnaires were obtained; (2) In the second round (May to July 2016), we invited 1172 experts to participate, and 402 accepted (a participation rate of $34.30 \%$ ). A total of 2591 questionnaires were obtained.

The second round involved more number of experts than the first round. Therefore, we used the results of the second round to carry out a marine engineering technology foresight analysis.

\subsection{Level and constraints of technical development}

\subsubsection{R\&D index}

As presented in Table 1, the average R\&D index of the 52 technology foresight options of marine engineering is 18.97 , which implies a relatively low R\&D level for China's marine engineering S\&T. The "seawater desalination technology and equipment for scaled use," as a subfield of seawater resource and marine energy comprehensive exploitation, has an R\&D index of 41.96; this is relatively high among the 52 options. The "deep-water submersible petroleum and gas exploitation system and technique," as a subfield of marine exploitation equipment, has an R\&D index of 3.17; this is the lowest among the 52 options.

\subsubsection{Constraints}

As demonstrated in Fig. 1, "talent, science, and technology resources" and "R\&D investment" are major constraint factors influencing marine engineering technical development; this is followed by "capability of industrial bases" and "coordination and cooperation." Currently, "standards and specifications" and "laws, regulations, and policies" exert limited influences on the development of marine engineering. Fig. 2 depicts the constraint factors affecting each subfield. For marine environment safety protection, "coordination and cooperation" is above "capability of industrial bases" and becomes the third constraint factor. Marine exploitation equipment is highly dependent on and sensitive to "capability of industrial bases." In addition, seawater resource

Table 1. R\&D index analysis of various subfields in marine engineering.

\begin{tabular}{|c|c|c|c|c|c|c|}
\hline Subfields & $\leq 20$ & $20-40$ & $40-60$ & $60-80$ & $>80$ & Average R\&D index \\
\hline $\begin{array}{l}\text { Marine environment multi-dimensional observation } \\
\text { technology and equipment }\end{array}$ & 11 & 3 & & & & 15.68 \\
\hline Submarine resource exploration and exploitation & 3 & 5 & & & & 19.03 \\
\hline Marine biological resource exploration and exploitation & 5 & 4 & & & & 20.07 \\
\hline $\begin{array}{l}\text { Seawater resource and marine energy comprehensive } \\
\text { exploitation }\end{array}$ & 2 & 5 & 1 & & & 23.05 \\
\hline Marine environment safety protection & 4 & 4 & & & & 22.29 \\
\hline Marine exploitation equipment & 4 & 1 & & & & 13.72 \\
\hline Total & 29 & 22 & 1 & & & 18.97 \\
\hline
\end{tabular}




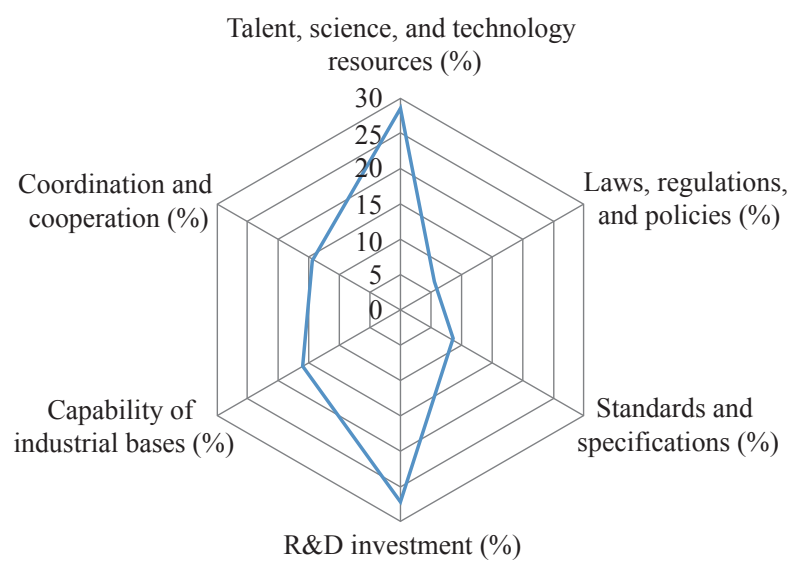

Fig. 1. Analysis of constraints in the field of marine engineering.

and marine energy comprehensive exploitation is subject to the significant constraint of "laws, regulations, and policies."

\subsection{Key technology items of marine engineering}

Through the statistical analysis of the technology foresight analysis results and seminar demonstration by marine engineering experts, the 12 most important technology directions were selected (Table 2).

\subsection{Expected time for realization of various technology items}

Fig. 3 depicts the anticipated time globally as well as in China for realizing the technology items and in China for social realization, with regard to the 52 technology foresight options

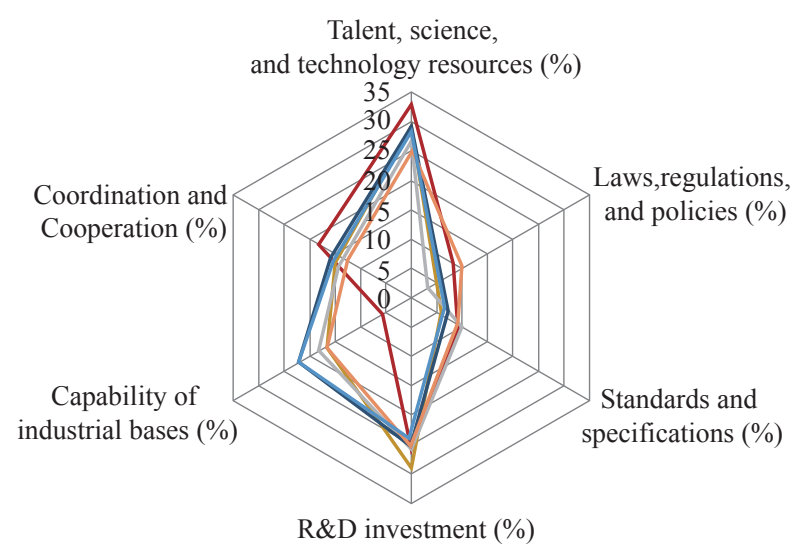

- Marine environment multi-dimensional observation technology and equipment

- Marine biological resource exploration and exploitation

- Marine environment safety protection

- Submarine resource exploration and exploitation

- Seawater resource and marine energy comprehensive exploitation

- Marine exploitation equipment

Fig. 2. Analysis of constraints in various subfields of marine engineering

for marine engineering science and technology. Globally, the anticipated technology realization time is between 2019 and 2025; 41 items (or $78.84 \%$ of all the technologies) will be realized by 2020-2022. In China, the anticipated technology realization time is between 2022 and 2029; 40 items (or 76.92\% of all the technologies) will be realized by 2024-2026. Meanwhile, in China, the anticipated social realization time will occur between 2023 and $2032 ; 41$ items (or $78.84 \%$ of all the technologies) will occur between 2026 and 2029.

Table 2. Key technology items of marine engineering.

\begin{tabular}{|c|c|c|}
\hline No. & Subfields & Technology items \\
\hline 1 & $\begin{array}{l}\text { Marine environment multi-dimensional observation } \\
\text { technology and equipment }\end{array}$ & Satellite-space-sea, surface-water-seabed, smart networking \\
\hline 3 & Submarine resource exploration and exploitation & Deep-sea polymetallic ores 3D comprehensive evaluation technique \\
\hline 4 & Submarine resource exploration and exploitation & Efficient and deep exploration technique for deep-sea polymetallic sulfide \\
\hline 5 & Marine biological resource exploration and exploitation & $\begin{array}{l}\text { R\&D and application technology for high value-added marine bio-enzyme } \\
\text { agents }\end{array}$ \\
\hline 6 & Marine biological resource exploration and exploitation & Exploitation technology for marine microorganism resources \\
\hline 7 & $\begin{array}{l}\text { Seawater resource and marine energy comprehensive } \\
\text { exploitation }\end{array}$ & Seawater desalination technology and equipment for scaled use \\
\hline 8 & $\begin{array}{l}\text { Seawater resource and marine energy comprehensive } \\
\text { exploitation }\end{array}$ & $\begin{array}{l}\text { Megawatt-level tidal current energy power generation technology and } \\
\text { equipment }\end{array}$ \\
\hline 9 & Marine environment safety protection & Marine data modelling S\&T \\
\hline 10 & Marine environment safety protection & $\begin{array}{l}\text { New technology for marine dynamic environment prediction and } \\
\text { forecasting }\end{array}$ \\
\hline 11 & Marine exploitation equipment & Deep-sea exploration and operational technology \\
\hline 12 & Marine exploitation equipment & $\begin{array}{l}\text { Deep-water submersible petroleum and gas exploitation system and } \\
\text { technique }\end{array}$ \\
\hline
\end{tabular}




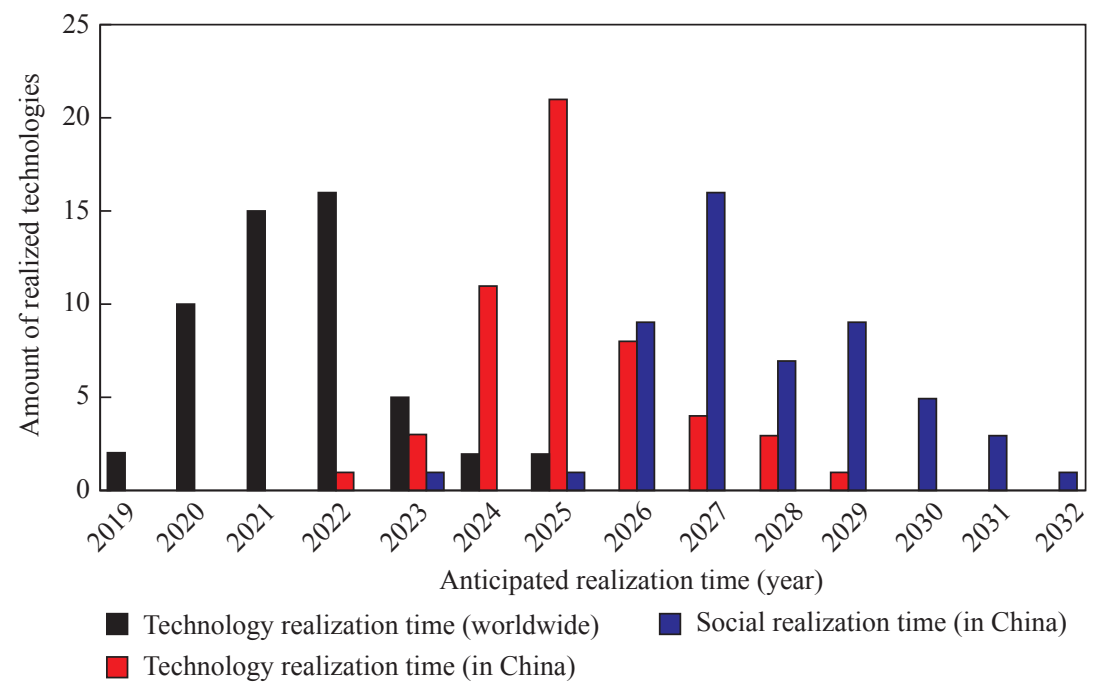

Fig. 3. Distribution of anticipated realization time.

\section{Development strategies for China's marine engineering S\&T for 2035}

\subsection{Thoughts and overall framework}

On the basis of China's Outline of the National Program for Medium- and Long-Term Scientific and Technological Development (2006-2020) and National Science and Technology Innovation Plan for the 13th Five-Year Plan Period (2016-2020), we propose the following roadmap for developing China's 2035 marine engineering S\&T. Focus should be placed on the strategic goal of becoming a maritime power and satisfying the strategic requirements of developing a marine economy, exploring deep/high seas marine resources, and safeguarding national marine rights and interests. An emphasis is placed on developing crucial technology categorized into six themes: technology and equipment for multi-dimensional observation of marine environment, submarine resource exploration and exploitation, marine biological resource exploration and exploitation, seawater resource and marine energy comprehensive exploitation, marine environment safety protection, and marine exploitation equipment.

Considering the current status (less developed) of marine engineering capabilities and in anticipation of the largely mature marine economy worldwide by 2035 , we propose a trinity task for China's marine engineering development; this trinity includes being endowed with the capabilities to independently research and develop marine engineering equipment, enhancing the capabilities to exploit marine resources, and establishing a technical safeguarding system to ensure marine safety and strategic interests (Fig. 4). The overall development framework consists of the following elements: (1) undertake due efforts to

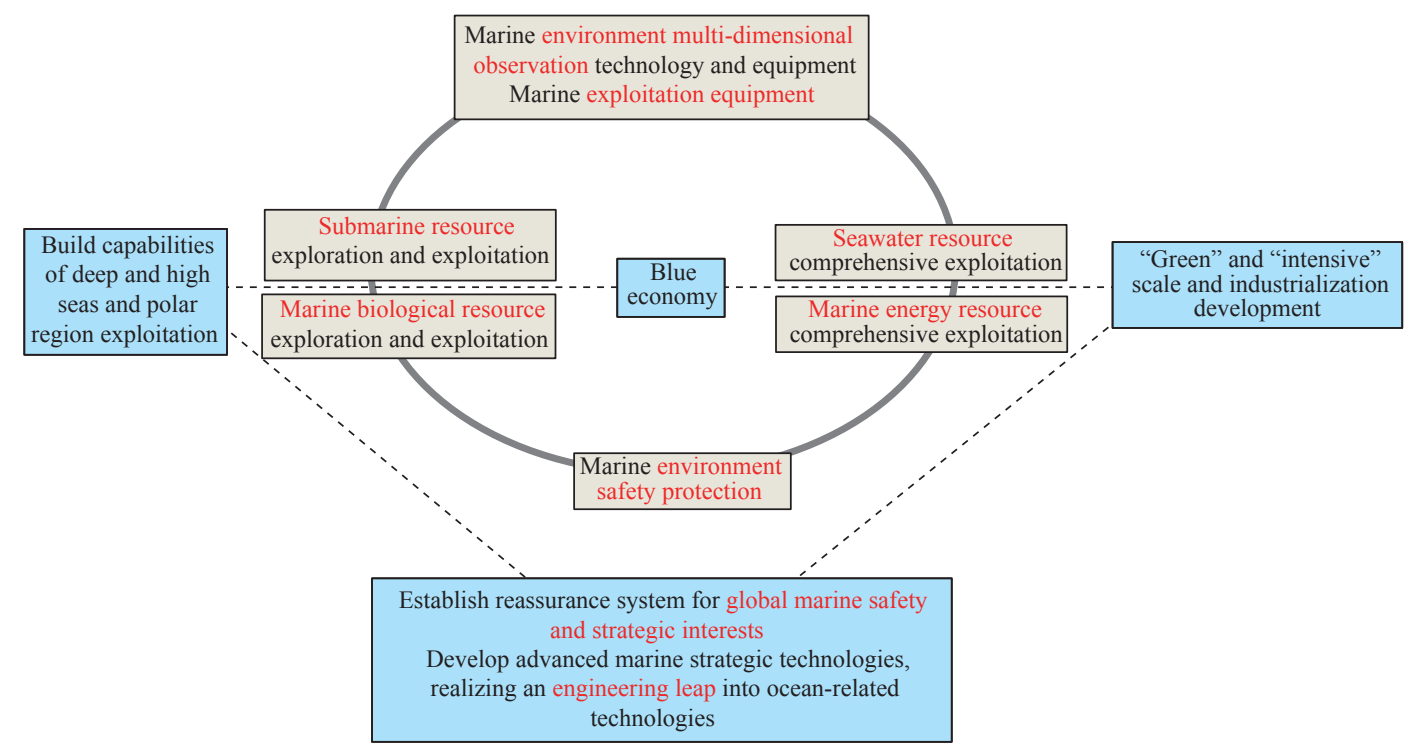

Fig. 4. Development framework for marine engineering S\&T for 2035. 
develop proprietary marine engineering equipment and enhance capabilities of independent marine engineering innovation; (2) establish a comprehensive marine management service reassurance system, which is IT-based, service-oriented, and intelligent (SmartOcean), to serve marine economic development, national marine safety, and marine ecological environment protection and to industrialize the marine information service; (3) boost marine economy, cultivate all-round exploration and exploitation competencies in the fields of submarine resources, marine biological resources, and seawater and marine energy resources and ultimately evolve into a blue economy industry; (4) Tap into the lead function of national strategy and exploit the advantage of focusing on major issues by taking complete advantage of markets and entrepreneurship, rationalize the efforts of addressing key technical bottlenecks to realize corner overtaking and achieve breakthroughs in marine exploration and exploitation technology, and mold the new marine economy into a pillar of the future national economy.

\subsection{Objectives and roadmap}

The overall objectives are to achieve self-reliance in marine engineering equipment and technology in order to develop intelligent monitoring competencies and safety reassurance network systems for the global marine environment, obtain reasonable marine space resources in order to extend seafloor ores, develop energy and marine biological resource exploration and exploitation capabilities in deep and high seas, advance the utilization of seawater resource and the comprehensive use of marine energy to an industrial scale, and realize a significant increase in the size of the marine economy and industry. The development roadmap is illustrated in Fig. 5.

\subsubsection{Marine environment multi-dimensional observation} technology and equipment

A global ocean observation system will be developed and put into effective operation to acquire multi-dimensional observation capabilities in relation to multiple sea surface and underwater factors globally. Effort will be put into formulating an intelligent, networked, multi-dimensional observation system involving satellite-space-sea means and surface-water-seabed dimensions, which will enable continuous $6 \mathrm{~h}$ observations worldwide and $1 \mathrm{~h}$ observations across China's coastal waters at crucial marine regions. A comprehensive marine environment information service platform and a "SmartOcean" system based on predictions, forecasts, and expert knowledge will be developed to provide real-time information for marine exploration, marine economy, and military operations.

\subsubsection{Submarine resource exploration and exploitation}

In the coming two decades, effort will be put into solving fundamental scientific issues that constrain seafloor ore mining.
The geological theory system, in relation to seafloor ore mineralization, will be improved. A deep-water engineering technical innovation platform will be created, and a technical system for fine exploration of seafloor ores will be developed. A sea trial and pilot use of $1000 \mathrm{~m}$ level deep-sea ore collection and transport technology will be completed. Pilot projects involving exploration and exploitation technology for seafloor ores and gas hydrates will be established, and an industrial system for deep-water engineering will be fostered to enhance the selfreliant competencies of seafloor ore exploitation.

\subsubsection{Marine biological resource exploration and exploitation}

Deep-blue marine fishery capabilities will be strengthened by establishing multi-dimensional fish-finding technical and big data systems and by fostering self-reliant R\&D bases for deep and high seas fish resources exploration equipment and shipborne fish processing equipment. New marine organism industries will be cultivated by exploring marine biological gene resources, microorganism resources, and organism-based functional materials as well as by exploring and exploiting marine biological resources at deep/high seas and polar regions. A large amount of proprietary marine genetic engineering products that satisfy China's key demands and are marketable in international markets will be rolled out. Platforms with innovative technology for R\&D, with regard to marine bio-enzymes, and new technical systems for their implementation will be established.

\subsubsection{Seawater resource and marine energy comprehensive} exploitation

Significant improvement will be achieved in seawater resource exploitation technology and in the industries of environmental innovation, innovation capabilities, technical processes, equipment industrialization, and application scale, attaining the most advanced level globally. Moreover, these technologies and equipment will be made available to the global market in order to foster global competitive advantages. The bottlenecks to critical technology for productizing marine energy power generation equipment will be eliminated, and the industry will attain advanced international status. The marine energy industry will be of considerable scale, lay solid foundations for the sizable exploitation of marine energy, and establish a high-end marine energy equipment manufacturing industry. This will provide alternative energy sources to power China's energy structure transformation and aid to secure its due share on the international marine energy market.

\subsubsection{Marine environment safety protection}

A marine environment safety protection system based on China's self-reliant marine operation will be established. Forecasts regarding China's dynamic marine and ecological environment will be more precise; thus, the use of important marine channels and the construction of key marine engineering projects will be 


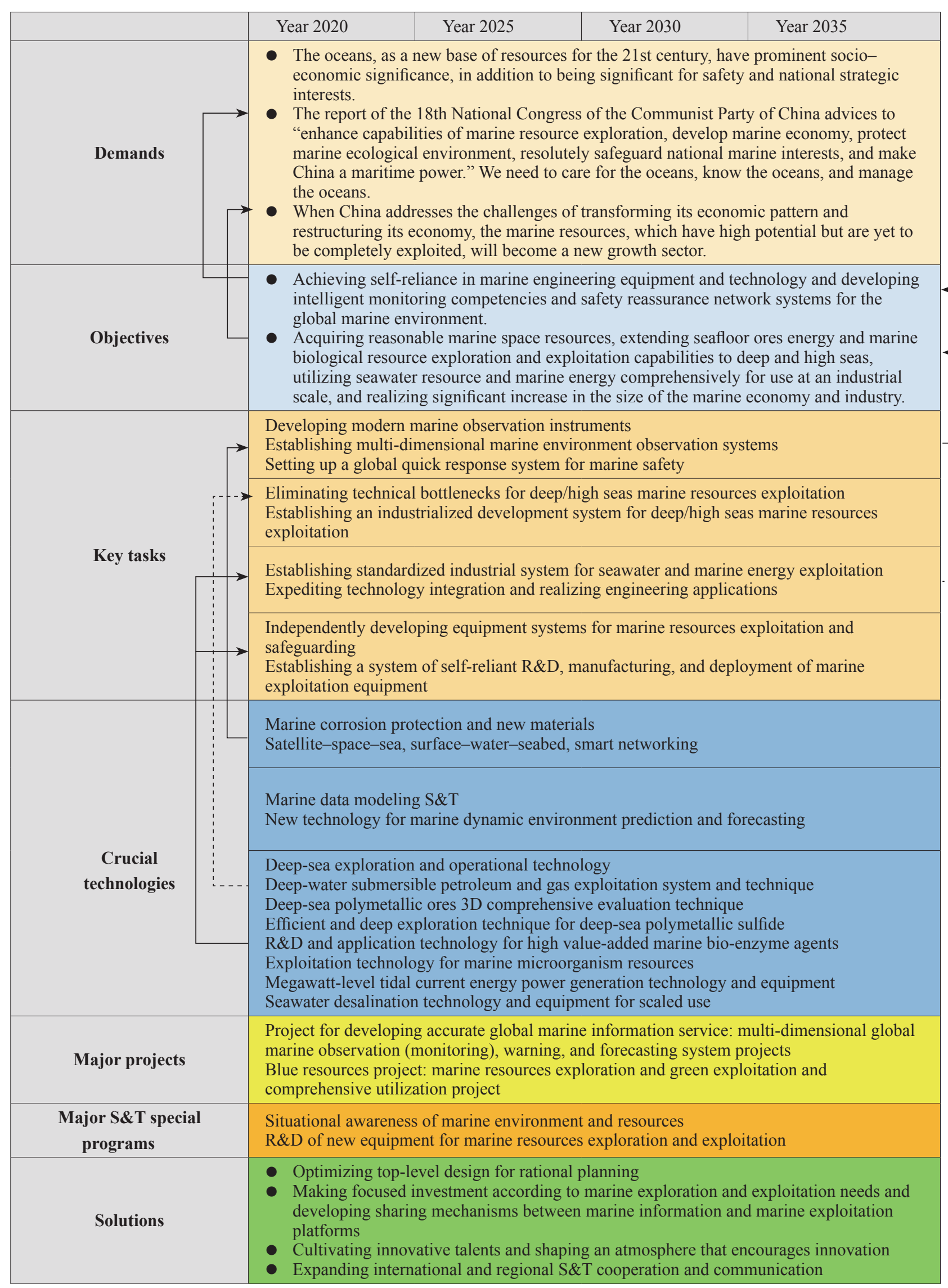

Fig. 5. Development roadmap for China's marine engineering S\&T for 2035. 
safeguarded. The risk management and impact assessment of significant marine emergencies and disasters will be performed faster and more accurately. The restoration and restructuring (both human and natural) of reef ecological systems will be enhanced; thus, relevant resource protection and ecological safety protection will be improved. A high-precision survey of the continental shelf and seabed will provide the basis for continental shelf delimitation.

\subsubsection{Marine exploitation equipment}

The R\&D capabilities for seabed ore and gas hydrate exploitation equipment and state-of-the-art marine exploitation equipment in relation to marine biology resources, seawater, and marine energy will be significantly strengthened; this will make it feasible to provide world class proprietary equipment for marine exploitation and scientific research activities. China will hold major shares on the international market for marine exploitation equipment and will thus function as a technical leader and standard setter. Self-reliant innovation capabilities for key systems and associated equipment will be intensified significantly, with competitive products leading the industry and less competitive products approaching advanced, global standards. In the seabed petroleum and gas sector, over $80 \%$ of the shipboard exploitation equipment and auxiliary plants will be manufactured in China. The intelligent manufacturing pattern will be widely adopted, and the marine exploitation equipment manufacturing industry will shift from production-based to service-based.

\section{Suggestions on major marine S\&T programs}

In July 2016, China announced the National Science and Technology Innovation Plan for the 13th Five-Year Plan Period, which encompasses several 2030-oriented major S\&T programs and projects including the major S\&T program of a marine space station. Based on the objective of becoming a maritime power and in accordance with the marine engineering S\&T development strategy, we recommend launching a series of major interdisciplinary programs.

\subsection{Major projects}

6.1.1 Project for developing accurate global marine information service: multi-dimensional global marine observation (monitoring), warning, and forecasting system projects

From a global perspective, the target is to develop a technical system that will safeguard national security and strategic interests. By developing a multi-dimensional observation network and a proprietary marine numerical forecasting system, an accurate marine information service system will be established with the main objective of performing business-oriented marine observation, while catering to scientific research and serving economic exploitation and maritime military operations. Concurrently, a multi-dimensional global marine observation (monitoring) and warning/forecasting system, which will serve marine environment and resource exploration in addition to focusing on oceans with regard to the "21st Century Maritime Silk Road" and key regions closely related to China in the western Pacific Ocean and the Indian Ocean, will be established to provide public marine products for utilization in marine economic activities, ocean rights protection activities, and naval military operations for satisfying the strategic needs of national economic development, protection of marine rights and interests, and development of marine sciences.

6.1.2 Blue resources project: marine resources exploration and green exploitation, and comprehensive utilization projects

The blue resources project aims to intensify the exploration and exploitation of coastal and offshore resources and to strengthen the use of resources at high seas and international seafloors. A multi-means competency system for exploration and detailed survey of global marine mineral resources, biological (e.g., fishery) and ecological resources, and space resources will be established. A system for R\&D and manufacturing of marine exploitation equipment will be developed. Efforts will be made to achieve technical innovation and the industrialization of seafloor mineral resources, marine biomedicines, seawater desalination, and marine renewable energy. Upgrades and green adaptation will be implemented with regard to traditional marine industries such as marine fishery, marine shipbuilding, and salt extraction from seawater. The implementation of this major project will result in an all-round system of marine resource exploration and marine equipment R\&D; it will also result in several pilot platforms for the comprehensive utilization of seafloor mineral resources, marine organisms, seawater, and marine energy exploration and exploitation. Thus, the extensive exploitation of marine resources, fostering of emerging marine industries, promotion of China's industrial structure transformation, and contribution of marine economy to China's national economic growth will be realized at medium to high rates.

\subsection{Major S\&T special programs}

\subsubsection{Situational awareness of marine environment and} resources

This S\&T special program intends to eliminate the bottlenecks to core technology and equipment for marine monitoring, observation, and surveillance in the fields of corrosion-resistant materials, heterogeneous module integration and sensor-based integration, as well as marine big data applications. Intelligent marine environment observation (monitoring) technology and equipment will be fostered, with a focus on the R\&D of autonomous sensors, deep/high sea and seafloor observation platforms, and the core equipment of multi-dimensional observation networks. Additionally, it will aim at comprehensive multidimensional observation (monitoring) and warning/forecasting 
systems serving the marine environment and resource exploration. A higher localization rate of core equipment will be pursued. Top-level design will be carried out on marine environmental observation by integrated networks. Efforts will be made to develop core technology for structuring and integrating multidimensional marine observation networks, which will serve both civil and military purposes. Pilot multi-dimensional observation networks, which will integrate sources from space, aircraft, land, and sea, will be established. These efforts will jointly push China to attain a place among advanced countries in the field of marine environment observation and related equipment.

6.2.2 R\&D of new equipment for marine resources exploration and exploitation

The development of equipment is a necessary step toward the exploration of marine resources. All major marine countries in the world are intensifying their technical reserves of new equipment for marine resource exploitation. Marine equipment manufacturing constitutes a crucial strategic component of emerging industries and represents a key direction of the high-end equipment manufacturing industry. The industry is characterized by thorough knowledge and advanced technology, less consumption of material resources, higher growth potential, and reasonably comprehensive effects; therefore, it is leading the marine economy. This major S\&T special program focuses on several core issues such as new equipment R\&D mechanism, integration, intelligence, and orientation to deep/high seas. Thereby, it aims at establishing a complete $R \& D$ system for marine resources exploration and exploitation. The program will intensify China's industrial restructuring and help realize high-end marine exploration and exploitation equipment "made in China."

\section{Measures to expedite the emergence of China as a marine engineering power}

We propose the following measures to expedite the pace of making China a marine engineering power on the basis of the development roadmap of China 2035 marine engineering S\&T. Accordingly, it is considered that China's marine engineering S\&T is currently less developed, the industrialization structure and marine economic development are immature, and the industrialacademic-research cooperation is relatively diverse.

\subsection{Optimizing top-level design for rational planning}

Through top-level design, an overall strategic plan for the development of marine engineering S\&T shall be developed to provide guidance and intensify support where necessary. Meanwhile, the focus of each marine engineering innovation player, namely, scientific research institutes, institutes of higher education, and operational centers, shall be identified such that each innovation player can concentrate on its advantage while preventing duplication of work among the participants. By collective efforts, China will be able to accelerate its marine engineering S\&T development and achieve "corner overtaking."

\subsection{Making focused investment according to marine} exploration and exploitation needs and developing sharing mechanisms between marine information and marine exploitation platforms

High technology development in marine engineering is characterized by high difficulty, high risk, and high investment. For the great-leap-forward development of China's marine technology, an investment mechanism shall be established to stipulate a stable inflow of national investment into marine S\&T development, and to attract social investment from diversified sources to fund these R\&D activities. A service system for sharing basic data from various means of marine observation as well as for sharing a marine development platform shall be established to serve more innovation and entrepreneurship groups, according to the concept of focused funding and diverse sharing.

\subsection{Cultivating innovative talents and shaping an atmosphere} that encourages innovation

Effective medium- to long-term incentives and constraint systems shall be explored to provide a comprehensive technical platform and talent reserves for facilitating the sustainable development of the marine engineering sector. Technical professionals shall be encouraged to follow a variety of approaches toward transformative high-tech achievements, such as participating in the establishment of high-tech enterprises, to promote the transformation and industrialization of innovation.

\subsection{Expanding international and regional $S \& T$ cooperation and communication}

S\&T cooperation and communication shall occur widely at international and regional levels. Thus, the capacity for self-reliant innovation will be reinforced. On the one hand, efforts shall be made toward introducing international advanced marine engineering technology and encouraging spiral re-innovation based on introduced technology in order to achieve great-leap-forward development. China's scientists and research institutes shall be encouraged to participate, or take the lead, in major global or regional S\&T programs. On the other hand, we shall implement a strategy for developing the "21st Century Maritime Silk Road." Through the Asian Infrastructure Investment Bank projects, we shall closely monitor the demands of the international marine engineering market, achieve breakthroughs in core marine engineering technology, and intensify technical and industrial cooperation with other nations along the maritime Silk Road. Thus, 
a solid foundation will be laid for China's marine engineering S\&T and industries to become a world-class player [9].

\section{References}

[1] The State Council of the People's Republic of China. The 13th Five-Year Plan of national science and technology innovation plan [R]. Beijing: The State Council of the People's Republic of China, 2016. Chinese.

[2] Task Force for the Study on Development Strategy of China's Marine Engineering and Technology Comprehensive Research Group. Development strategy of marine engineering and technology power [J]. Strategic Study of CAE, 2016, 18 (2): 1-9. Chinese.

[3] The State Council of the People's Republic of China. The 13th Five-Year Plan of development of national ocean economy [R]. Beijing: The State Council of the People's Republic of China, 2016. Chinese.

[4] The State Council of the People's Republic of China. The outline of the national program for long and medium term scientific and technological development (2006-2020) [R]. Beijing: The State
Council of the People's Republic of China, 2012. Chinese.

[5] Wang F. Theory and practice of maritime power [J]. Strategic Study of CAE, 2016, 18 (2): 55-60. Chinese.

[6] Task Force for the Study on Development Strategy of China's Marine Engineering and Technology Marine Transportation Research Group. Research on China's development strategy for marine transportation engineering [J]. Strategic Study of CAE, 2016, 18 (2): 10-18. Chinese.

[7] Task Force for the Study on Development Strategy of China's Marine Engineering and Technology Marine Environment \& Ecological Engineering Research Group. Study on the development strategy of marine environment and ecological engineering in China [J]. Strategic Study of CAE, 2016, 18 (2): 41-48. Chinese.

[8] Xu Y R, Li P C. Developing tendency of unmanned underwater vehicles [J]. Chinese Journal of Nature, 2011, 33 (3): 125-132. Chinese.

[9] Chen M B, Han L M. Driving factors, areas of cooperation and mechanisms for international cooperation in the blue economy of the 21st-century maritime Silk Road [J]. Strategic Study of CAE, 2016, 18 (2): 98-104. Chinese. 